\title{
EFFECTS OF FASTING ON PRAVASTATIN DISPOSITION IN PERFUSED RAT LIVER
}

\author{
ATSUSHI KAWASE*, AYUMI HANDA, MASAHIRO IWAKI
}

Department of Pharmacy, Faculty of Pharmacy, Kindai University, 3-4-1 Kowakae, Higashi-osaka, Osaka 5778502, Japan

Email: kawase@phar.kindai.ac.jp

Received: 30 Aug 2016 Revised and Accepted: 05 0ct 2016

\begin{abstract}
Objective: Various nutrients such as glucose and cholesterol affect the expression of hepatic transporters. Although the pharmacokinetics of some drugs is affected by fasting, the fasting effects on drug hepatic disposition via alterations in transporters are unclear. Organic anion-transporting polypeptides and multidrug resistance-associated protein 2 (Mrp2/Abcc2) expressed in the liver are involved in hepatic disposition of pravastatin.
\end{abstract}

Methods: An in situ perfused rat liver system was established. The mRNA and protein levels of transporters in the liver were examined by real-time reverse transcription PCR and western blotting. The localization of Mrp2 in hepatocytes was determined by immunostaining.

Results: Pravastatin was rapidly eliminated from the perfusate. The cumulative biliary excretion amounts of pravastatin in fasting rats were significantly lower from 10 min compared with control. In fasting rats, the area under the plasma concentration-time curve $(A U C)_{0-\infty}$ of pravastatin in the perfusate was significantly decreased, and hepatic clearance $\left(C L_{h}\right)$ and hepatic corrected clearance $\left(C L_{c o r}\right)$ were significantly increased. The biliary clearance $\left(C L_{\text {bile }}\right)$ in fasting rats tended to decrease compared with that in control rats. Protein expression levels of transporters were unchanged after fasting. Confocal microscopy revealed a disruption of Mrp2 and Z0-1 colocalization in the liver of fasting rats.

Conclusion: The biliary excretion of pravastatin was inhibited by fasting via decreased Mrp2 localization on the canalicular membrane.

Keywords: Pravastatin, Fasting, Transporter, Perfusion, Starvation

(C) 2016 The Authors. Published by Innovare Academic Sciences Pvt Ltd. This is an open access article under the CC BY license (http://creativecommons.org/licenses/by/4. 0/) DOI: http://dx.doi.org/10.22159/ijpps.2016v8i12.14950

\section{INTRODUCTION}

Increases in plasma fatty acids and ketones, and a decrease in plasma glucose levels are observed upon fasting or short-term calorie restriction, and fatty acids are the main energy source during fasting [1, 2]. In mouse models of fasting, a 14-fold increase in triglyceride content was observed compared with the control [3]. Fasting also induces alterations in the gene expression of enzymes involved in lipid metabolism $[4,5]$. It has been reported that drug pharmacokinetics was affected by fasting $[6,7]$.

Solute carrier (SLC) and ATP-binding cassette (ABC) transporters expressed in the liver are involved in hepatic disposition of some drugs. For example, organic anion-transporting polypeptides (Oatp/Slc21 family) in SLC transporters are expressed on the basal side of hepatocytes and transport various drugs such as 3-hydroxy3-methylglutaryl coenzyme A(HMG-CoA) reductase inhibitors (statins) [8-11]. Multidrug resistance-associated protein 2 (Mrp2/Abcc2) in ABC transporters is expressed on the apical side of hepatocytes, and transports drugs and drug metabolites such as glucuronides [12-14]. Various nutrients such as glucose and cholesterol affect the expression of hepatic transporters [15-18]. However, it is unclear whether fasting affects hepatic drug disposition via alterations in the expression of transporters.

Pravastatin is an HMG-CoA reductase inhibitor and is a substrate of Oatp and Mrp2. Pravastatin is selectively distributed to the liver followed by enterohepatic circulation after biliary excretion in an unchanged form $[12,13]$. Therefore, pravastatin is well suited for examining the effects of fasting on hepatic disposition of drugs via alterations in the expression and function of transporters.

We examined the hepatic disposition of pravastatin in an in situ perfused rat liver system. The in situ perfused rat liver model enables investigation of drug hepatic transport. We also determined the mRNA and protein levels of Oatp1a1, Mrp2, Mrp3, bile salt export pump (Bsep), nuclear receptor constitutive androstane receptor (CAR), and pregnane $X$ receptor (PXR) in the liver, and the localization of Mrp2 in hepatocytes based on the known internalization of Mrp2 from the canalicular membrane [19-21].

\section{MATERIALS AND METHODS}

\section{Compounds and reagents}

Pravastatin (sodium salt) and imipramine as an internal standard for (high performance liquid chromatography) HPLC analysis were purchased from LKT Laboratories (St. Paul, MN, USA) and Sigma Aldrich (St. Louis, MO, USA), respectively. Rabbit polyclonal antiOatp1 antibody (Alpha Diagnostic Intl., San Antonio, TX, USA), mouse monoclonal anti-Mrp2 antibody (M III-6) (Abcam, Cambridge, UK), mouse monoclonal anti-Mrp3 antibody ( $\mathrm{M}_{3} \mathrm{II}-9$ ) (Abcam), rabbit polyclonal anti-Bsep antibody (Abcam), mouse monoclonal anti- $\beta$-actin (Acris Antibodies, Herford, Germany), peroxidase-labeled goat anti-mouse IgG antibody (KPL, Gaithersburg, MA, USA), peroxidase-labeled rabbit anti-rat IgG antibody (Life technologies), rat monoclonal anti-zonula occuludens (ZO)-1 antibody (JS007) (Novus Biologicals, Littleton, CO, USA), CF568 goat anti-mouse IgG antibody (Biotium, Hayward, CA, USA), and CF633 goat anti-rat IgG antibody (Biotium) were commercially obtained. TRIzol and Mem-PER Eukaryotic Membrane Protein Extraction Kit were obtained from Life Technologies (Carlsbad, CA, USA) and Thermo Fisher Scientific (Waltham, MA, USA), respectively. BCA Protein Assay Kit was purchased from Pierce Biotechnology (Rockford, IL, USA). All other chemicals and solvents were of the best purity commercially available or of HPLC grade.

\section{Animals}

Eight-week-old male Sprague-Dawley rats were purchased from Japan SLC (Shizuoka, Japan). Animals were housed in a temperaturecontrolled room with free access to standard laboratory chow (MF diet, Oriental Yeast, Tokyo, Japan) and water. Rats were fasting for $48 \mathrm{~h}$ with only water as fasting group. Blood samples $(100 \mu \mathrm{l})$ were collected from the tail vein in the animals at $48 \mathrm{~h}$ after onset of fasting. The plasma levels of ketone were determined by Osaka Kessei Research Laboratories (Osaka, Japan). The study protocol was approved by the Committee for the Care and Use of Laboratory Animals of the School of Pharmacy of Kindai University (Osaka, Japan) (KAPS-26-010). 


\section{In situ rat liver perfusion}

In situ rat liver perfusion was performed by the procedure described in previous report [22]. Briefly, the perfusion medium volume was $100 \mathrm{ml}$ consisted of Krebs-Ringer-bicarbonate solution with 24 $\mu \mathrm{mol} / \mathrm{l}$ taurocholic acid. Rats cannulated in the bile duct, hepatic portal vein, inferior vena cava were perfused at a flow rate of 26 $\mathrm{ml} / \mathrm{min}$. Pravastatin was added to the perfusate reservoir (10 $\mu \mathrm{mol} / \mathrm{l})$. Perfusate samples $(1 \mathrm{ml})$ were collected from the recirculating reservoir at $0,0.5,1,1.5,2,3,5,7$, and $10 \mathrm{~min}$ and the same volume of blank perfusion medium was immediately added to the perfusate. Bile samples were collected up to $60 \mathrm{~min}$. Each sample was flash frozen in liquid nitrogen and preserved at $-80^{\circ} \mathrm{C}$.

\section{Assay procedure}

Pravastatin concentrations were measured using HPLC (SIL-10A, LC-10AD, CT0-10A, SPD-10A, and CR-3A, Shimadzu, Kyoto, Japan). For HPLC analysis of the perfusate, an internal standard (80 $\mu$ l, 20 $\mu \mathrm{g} / \mathrm{ml}$ of imipramine) and deproteinized with $200 \mu \mathrm{l}$ methanol were added to $200 \mu \mathrm{l}$ of perfusate. For bile samples, $10 \mu \mathrm{l}$ of bile was diluted with $190 \mu \mathrm{l}$ water, an internal standard $(80 \mu \mathrm{l}, 20 \mu \mathrm{g} / \mathrm{ml}$ of imipramine) and deproteinized with $200 \mu \mathrm{l}$ methanol. After centrifugation for $10 \mathrm{~min}$ at $3,000 \times \mathrm{g}$, the supernatant was injected into the HPLC analyzer.

HPLC analysis was performed using a reverse-phase column (Inertsil ODS-2, $5 \mu \mathrm{m}, 250 \times 4.6 \mathrm{~mm}$; GL Sciences, Tokyo, Japan), using a Shimadzu HPLC system equipped with a UV detector. The column temperature was set at $35^{\circ} \mathrm{C}$ and UV detector set at $238 \mathrm{~nm}$. The mobile phase [methanol/water $(60: 40, \mathrm{v} / \mathrm{v})$ containing $0.1 \%$ acetic acid and $0.1 \%$ triethylamine] was pumped at a flow rate of 0.7 $\mathrm{ml} / \mathrm{min}$. Standard curves for pravastatin metabolites were linear over the concentration range of $0.1-100 \mu \mathrm{mol} / \mathrm{l}(\mathrm{r}>0.93$ and $<10 \%$ error).

\section{Pharmacokinetic analysis}

Pharmacokinetic analyses were performed using statistical moment analysis. Area under the plasma concentration-time curve $(A U C)$ was calculated from zero to $10 \mathrm{~min}\left(A U C_{0-10}\right)$ using the linear trapezoidal rule. $A U C_{10-\infty}$ was estimated as $C_{10} \mathrm{~min} / k_{e}$ in which $C_{10 \min }$ and $k_{e}$ are the pravastatin concentrations in perfusate at $10 \mathrm{~min}$ and the elimination rate constant, respectively. Mean residence time from zero to $\infty\left(M R T_{0-\infty}\right)$ was calculated as the ratio of $A U M C_{0-\infty}\left(A U C_{0-\infty}\right.$ times time versus time curve) and $A U C_{0-\infty} C L_{h}$ was calculated as the pravastatin dose divided by the $A U C_{0-\infty}$. The (biliary clearance) $C L_{\text {bile }}$ was calculated as the cumulative amounts of pravastatin excreted in bile at $60 \mathrm{~min}$ divided by the $A U C_{0-\infty}$. Hepatic corrected clearance $\left(C L_{c o r}\right)$ represented $C L_{h}$ adjusting for liver weight in rats.

\section{Determination of mRNA levels by real-time reverse transcriptase polymerase chain reaction (RT-PCR)}

Total RNA was extracted from liver samples using TRIzol. mRNA expression was measured using RT-PCR, as described previously $[23,24]$. The oligonucleotide sequences for each mRNA target are shown in table 1. Data were analyzed using ABI Prism 7000 SDS software (Life Technologies), using the multiplex comparative method.

\section{Determination of protein levels by western blot}

Membrane proteins were extracted from the livers using Mem-PER Eukaryotic Membrane Protein Extraction Kit. Protein concentrations were measured using a BCA Protein Assay Kit. Sodium dodecyl sulfate-polyacrylamide gel electrophoresis (SDS-PAGE) was performed using $7.5 \%$ e-Pagell (Atto, Tokyo, Japan) and $5 \mu \mathrm{g}$ membrane protein per well. Resolved proteins were transferred onto Hybond-P polyvinylidene difluoride membranes (GE Healthcare, Milwaukee, WI, USA). Immunoreactive Oatp1a1, Mrp2, Mrp3, and Bsep proteins were detected using antibodies, and an ECL Plus Western Blotting Detection system (GE Healthcare).

\section{Immunofluorescence analysis}

The livers were perfused-fixed by $4 \%$ paraformaldehyde in 0.1 $\mathrm{mol} / \mathrm{l}$ PBS for $10 \mathrm{~min}$. The excised livers were immersed in $4 \%$ paraformaldehyde in $0.1 \mathrm{~mol} / \mathrm{l}$ PBS for $3 \mathrm{~h}, 10 \%$ sucrose for $3 \mathrm{~h}$, $20 \%$ sucrose for $3 \mathrm{~h}$ and $30 \%$ sucrose for overnight. The tissue blocks embedded in Tissue-Tek O. C. T. compound (Sakura Finetek, Tokyo, Japan) were snap-frozen in liquid nitrogen. The cryosections ( $6 \mu \mathrm{m}$-thick) were prepared at $-20^{\circ} \mathrm{C}$ by cryostat (Leica CM3050S, Leica, Wetzlar, Germany). The sections on the slides were hydrated in PBS and blocked for 30 min with 3\% BSA/PBS. After wash with $0.1 \%$ BSA/PBS, the slides were incubated with anti-Mrp2 antibody and anti-ZO-1antibody for $1 \mathrm{~h}$. After wash with $0.1 \%$ BSA/PBS, the slides were incubated with CF568 goat anti-mouse IgG for anti-Mrp2 antibody and CF633 goat anti-rat IgG for anti-ZO-1 antibody for $1 \mathrm{~h}$. The samples were mounted in VECTASHIELD (Vector Laboratories, CA, USA) and were subjected to confocal laser scanning microscope (FV10i-DOC, OLYMPUS, Tokyo, Japan).

\section{Statistical analyses}

Significant differences between mean values were determined by Student's t-test using GraphPad Prism software (La Jolla, CA, USA). Significance levels were determined at $p<0.05$.

\section{RESULTS}

\section{Animals}

The liver weight, body weight, and the liver to body weight ratio in fasting rats were significantly decreased compared with the control (table 2). In fasting rats, the plasma cholesterol levels were significantly decreased and the plasma ketone levels were significantly increased compared with the control rats (table 2). In particular, approximately 10 times higher plasma ketone levels were observed in fasting rats.

\section{In situ rat liver perfusion}

To clarify the effects of fasting on the hepatic concentration of pravastatin, we established an in situ perfused rat liver system. The perfusate concentrations of pravastatin and the cumulative amounts of pravastatin excreted into the bile are shown in fig. 1a and b, respectively. Pravastatin was rapidly eliminated from the perfusate and the perfusate concentration reached less than $10 \%$ of the dose after $10 \mathrm{~min}$ of perfusion. The perfusate concentrations of pravastatin in fasting rats tended to be lower than those in control rats (fig. 1a). The cumulative biliary excretion amounts of pravastatin in the fasting rats were significantly lower from $10 \mathrm{~min}$ compared with the control (fig. 1b). At $60 \mathrm{~min}$, the cumulative biliary excretion amounts of pravastatin in the control rats and fasting rats were $0.32 \pm 0.016 \mathrm{mg}$ and $0.22 \pm 0.026 \mathrm{mg}$, respectively. The noncompartmental pharmacokinetic parameters are summarized in table 3. In the fasting rats, the $A U C_{0-\infty}$ of pravastatin in the perfusate was significantly decreased, and the $C L_{h}$ and $C L_{c o r}$ were significantly increased compared with the control. The biliary clearance $C L_{b i l e}$ in the fasting rats tended to decrease compared with that in the control rats $(p=0.08)$, although the bile flow rate was similar in the control and fasting rats $(0.93 \pm 0.05 \mu \mathrm{l} / \mathrm{min}$ in the control rats and $0.86 \pm 0.06$ $\mu \mathrm{l} / \mathrm{min}$ in the fasting rats).

\section{Determination of mRNA and protein levels of transporters}

Some transporters such as Oatp and Mrp2 are involved in hepatic disposition of pravastatin. To clarify whether fasting affects the hepatic expression of transporters, the mRNA and protein expression levels of transporters were determined (fig. 3). The mRNA levels of Mrp2 and Bsep in the fasting rats significantly decreased to approximately $40 \%$ of those in the control rats.

However, the protein expression levels of these transporters were unchanged by fasting. Small changes in the mRNA levels of nuclear receptors such as $P X R$ and CAR were observed in the fasting rats. 
(a)

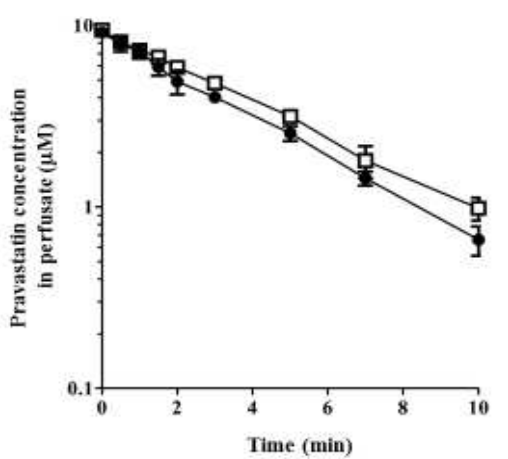

(b)

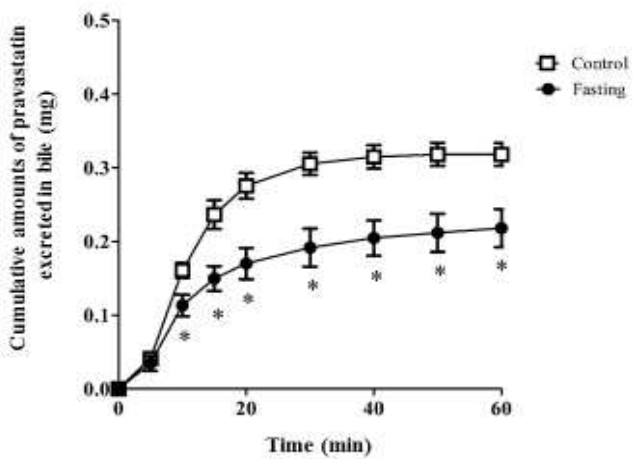

Fig. 1: Concentrations of pravastatin in the perfusate (a) and cumulative amounts of pravastatin in bile (b) after addition of pravastatin to the perfusion solution $(10 \mu \mathrm{mol} / \mathrm{l})$. The results are expressed as the mean $\pm \mathrm{SD}$ of $n=3-5 .{ }^{*} p<0.05$ vs corresponding control
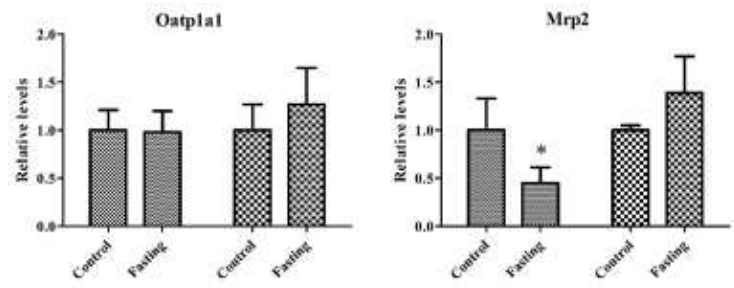

Bse
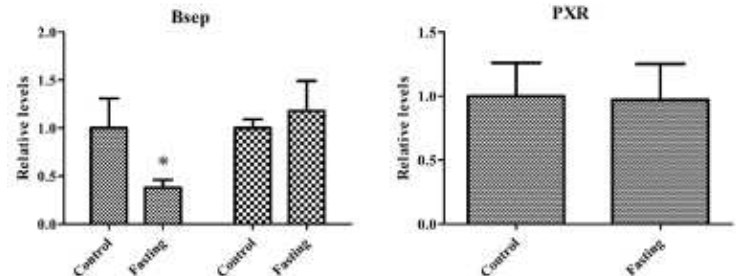

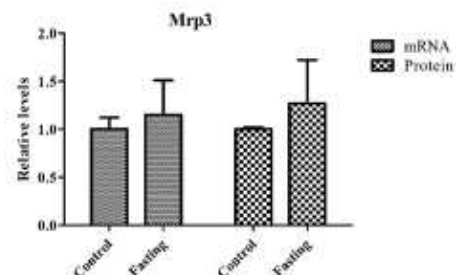

CAR

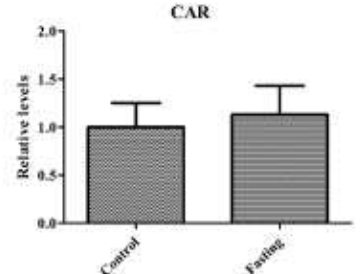

Fig. 2: Relative mRNA and protein levels of Oatp1a1, Mrp2, Mrp3 and Bsep in the liver of control and fasting rats. The results are expressed as the mean $\pm S D$ of $n=3-4$. Significant differences between control and fasting rats are indicated $\left({ }^{*} p<0.05\right)$

\section{Immunofluorescence analysis}

Even though the Mrp2 expression did not change, the localization of Mrp2 in hepatic cryosections of control and fasting rats was examined, because the intracellular localization of Mrp2 is a determinant of Mrp2 transport activity. Fig. 2 illustrates the localization of Mrp2 (red) and ZO-1 (blue) in the liver of control and fasting rats. Colocalization of Mrp2 and ZO-1 was observed in the control rats. In contrast, the confocal image of fasting rat's cryosections revealed a disruption in colocalization of Mrp2 and ZO1 in the liver, suggesting that the function of Mrp2 decreased without changes in Mrp2 expression levels.
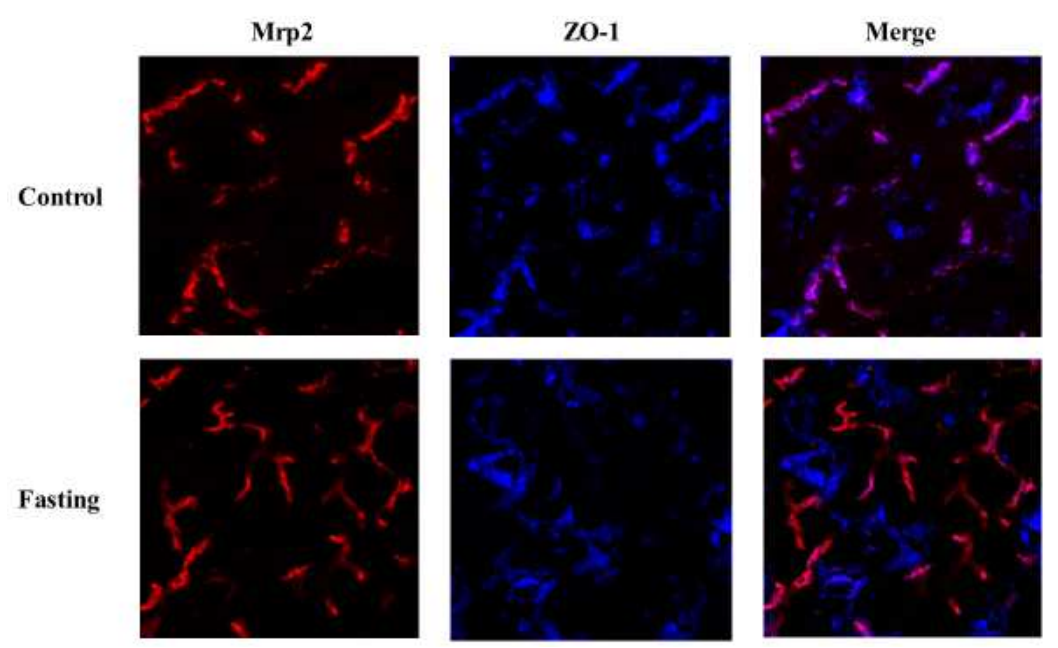

Fig. 3: Localization of Mrp2 (red) and ZO-1 (blue) expression in liver of control and fasting rats 
Table 1: Primer sequences used in PCR assays

\begin{tabular}{|c|c|}
\hline Gene & Primer sequence $\left(5^{\prime}-3^{\prime}\right)$ \\
\hline \multirow[t]{2}{*}{ Oatp1a1 } & CTGCCTGCCTTCTTCATTCTGA \\
\hline & GCTTTCCTTCTCTCCGAGCATC \\
\hline \multirow[t]{2}{*}{ Mrp2 } & CTCGGTCTTATGCGGCGTATT \\
\hline & TCTGGAAACCGTAGGAGACGAA \\
\hline \multirow[t]{2}{*}{ Mrp3 } & TGAAGTTCAAAGACTCCCGCA \\
\hline & TCTACCTGCTCCAAGAAGGTGG \\
\hline \multirow[t]{2}{*}{ Bsep } & CATCATTGCGGCCTTGCT \\
\hline & GCGAATCCCGTCAACATTTT \\
\hline \multirow[t]{2}{*}{$P X R$} & GACGGCAGCATCTGGAACTAC \\
\hline & TGATGACGCCCTTGAACATG \\
\hline \multirow[t]{2}{*}{ CAR } & CCACGGGCTATCATTTCCAT \\
\hline & CCCAGCAAACGGACAGATG \\
\hline \multirow[t]{2}{*}{$18 S$ ribosomal RNA } & CGCCGCTAGAGGTGAAATTC \\
\hline & CCAGTCGGCATCGTTTATGG \\
\hline
\end{tabular}

Table 2: Liver weight, body weight, liver to body weight, plasma cholesterol level, and plasma ketone in control and fasting rats

\begin{tabular}{lllll}
\hline & Liver weight (g) & Body weight (g) & Liver weight/body weight & Cholesterol (mg/dl) \\
\hline Control & $7.16 \pm 0.741$ & $199 \pm 8.08$ & $0.036 \pm 0.005$ & $69.8 \pm 5.63$ \\
Fasting & $4.62 \pm 0.358^{* * *}$ & $168 \pm 8.67^{* * *}$ & $0.027 \pm 0.002^{* *}$ & $30.3 \pm 1.53^{* * *}$ \\
\hline
\end{tabular}

The results are expressed as the mean \pm SD of $n=3-6$. Significant differences between control and fasting rats are indicated $(* * p<0.01$ and $* * * p<0.001)$.

Table 3: Parameters describing the disposition of pravastatin obtained from statistical moment analysis of the perfused rat liver

\begin{tabular}{lllll}
\hline & $\boldsymbol{A U} \boldsymbol{C}_{\mathbf{0}-\infty}(\boldsymbol{\mu} \mathbf{g} / \mathbf{m l} \cdot \mathbf{m i n})$ & $\boldsymbol{M R T}_{\mathbf{0}-\infty}(\mathbf{m i n})$ & $\boldsymbol{C L}_{\boldsymbol{h}}(\mathbf{m l} / \mathbf{m i n})$ & $\boldsymbol{C L}_{\text {cor }}(\mathbf{m l} / \mathbf{m i n} / \mathbf{g}$ liver$)$ \\
\hline Control & $18.5 \pm 1.00$ & $4.37 \pm 0.39$ & $24.1 \pm 1.28$ & $3.76 \pm 0.31$ \\
Fasting & $15.6 \pm 1.21^{*}$ & $3.84 \pm 0.31$ & $29.8 \pm 3.07^{*}$ & $5.82 \pm 0.32^{* *}$ \\
\hline
\end{tabular}

The results are expressed as the mean \pm SD of $n=3-5$. Significant differences between control and fasting rats are indicated $\left({ }^{*} p<0.05\right.$ and $\left.* * p<0.01\right)$.

\section{DISCUSSION}

In fasting rats, the plasma ketone levels were significantly increased compared with the control (table 2), suggesting that $48 \mathrm{~h}$ of fasting was enough to induce ketone production utilized as alternative energy substrates to glucose. It has been reported that $48 \mathrm{~h}$ of fasting resulted in stimulation of gluconeogenesis and reduction in blood glucose levels in rats [25-27]. The liver to body weight ratio was significantly decreased in addition to a decrease in liver and body weight of fasting rats, indicating that the loss of liver weight in fasting rats was larger than that of the body weight. The perfusate concentrations of pravastatin and the $A U C_{0-\infty}$ in fasting rats was significantly decreased compared with the control rats, although a relatively rapid elimination of pravastatin from the perfusate was observed in both control and fasting rats (fig. 1). The rate of elimination of pravastatin from the perfusate was comparable to the flow rate $(26 \mathrm{ml} / \mathrm{min})$, indicating that the elimination of pravastatin from the perfusate was limited by the flow rate via Oatp1a1 [9-11]. The increases in $C L_{c o r}$ in the fasting rats were larger than those of $C L_{h}$, which was normalized by the liver weight, indicating that the removal ability of pravastatin per hepatic unit was reduced by fasting for $48 \mathrm{~h}$.

The cumulative amounts of pravastatin excreted into the bile were significantly decreased in the fasting rats (fig. 1b) without changes in bile flow. The cumulative biliary excretion amounts of pravastatin in the control and fasting rats at $60 \mathrm{~min}$ were approximately $72 \%$ and $49 \%$, respectively, indicating that fasting markedly inhibited the biliary excretion of pravastatin. The hepatic concentrations of pravastatin could possibly be elevated, because of the decreased biliary excretion of pravastatin and the unchanged pravastatin concentrations in the perfusate of fasting rats. The changes in the hepatic concentrations of pravastatin in fasting rats could affect the desired or adverse effects of pravastatin.

Transporters such as Mrp2 are involved in the biliary excretion of pravastatin. A high-fat diet increased hepatic Mrp2 protein levels in mice [16]. High-fat and high-sucrose diets significantly upregulated hepatic ABC transporter g5/g8 expression [17]. The hepatic Pglycoprotein expression levels were significantly decreased in rats fed a 4\% cholesterol diet for $14 \mathrm{~d}$ [15]. However, it is unclear whether fasting affects the hepatic expression of transporters. The protein levels of transporters in the fasting rats were unchanged (fig. 3). However, not only the expression levels, but also the Mrp2 localization on bile canaliculus is important for the transport activity of Mrp2. Therefore, the expression levels of Mrp2 in the liver do not necessarily reflect its transport activity. The colocalization of Mrp2 and ZO-1 was diminished by fasting (fig. 2), suggesting that fasting led to a decrease in cumulative biliary excretion amounts of pravastatin by disruption of Mrp2 localization on bile canaliculus.

Scaffold proteins such as ERM proteins (ezrin/radixin/moesin) have important roles in the membrane localization of Mrp2, which is internalized from the canalicular membrane [19-21]. For example, in radixin-deficient mice, the development of conjugated hyperbilirubinemia is associated with loss of Mrp2 from the canalicular membrane, similarly to Dubin-Johnson syndrome in humans [28]. Furthermore, Wang et al. have shown that knockdown of radixin by adenoviruses expressing siRNA in sandwich cultured rat hepatocytes resulted in a decrease in membrane localization and Mrp2 activity in the canalicular membrane [29]. Further studies are needed to clarify whether fasting affects the expression and activity of radixin in the liver.

It has been reported that fasting affects processes such as intestinal absorption [30], serum protein binding [31,32], and metabolism by cytochrome P450 (CYP) [33-36]. Fasting reduced the absorption rate constants of salicylate and antipyrine via intestinal weight loss and inhibition of intestinal cell proliferation [30]. Serum protein binding is a determinant of drug disposition. Albumin synthesis is rapidly inhibited by fasting in vivo and in situ [31, 32]. In rats, fasting for 36 h resulted in increased hepatic CYP1A2, CYP2D2 and CYP3A4 mRNA expression [36]. Our results showed that the process of biliary excretion via Mrp2 could be affected by fasting in addition to the processes of absorption, distribution and metabolism after drug application.

\section{CONCLUSION}

The present study demonstrated that fasting inhibited the biliary 
excretion of pravastatin. Our findings suggest that the fasting modulate the hepatic drug disposition and biliary excretion of drug and metabolites via Mrp2 and could affect the drug effects.

\section{ACKNOWLEDGEMENT}

This work was supported by the "Antiaging" Project for Private Universities, with a matching fund subsidy from the Japanese Ministry of Education, Culture, Sports, Science and Technology (MEXT). This research was also supported in part by the MEXTSupported Program for the Strategic Research Foundation at Private Universities, 2014-2018 (S1411037).

\section{CONFLICTS OF INTERESTS}

All authors have none to declare

\section{REFERENCES}

1. Mittendorfer B. Sexual dimorphism in human lipid metabolism. J Nutr 2005; 135:681-6.

2. Maughan RJ, Fallah J, Coyle EF. The effects of fasting on metabolism and performance. Br J Sports Med 2010;44:490-4.

3. Guan HP, Goldstein JL, Brown MS, Liang G. Accelerated fatty acid oxidation in muscle averts fasting-induced hepatic steatosis in SJL/J mice. J Biol Chem 2009;284:24644-52.

4. Saladin R, De Vos P, Guerre-Millo M, Leturque A, Girard J, Staels $B$, et al. Transient increase in obese gene expression after food intake or insulin administration. Nature 1995;377:527-9.

5. Kim JB, Sarraf P, Wright M, Yao KM, Mueller E, Solanes G, et al. Nutritional and insulin regulation of fatty acid synthetase and leptin gene expression through ADD1/SREBP1. J Clin Invest 1998;101:1-9.

6. Nakashima E, Yokogawa K, Ichimura F, Hashimoto T, Yamana T, Tsuji A. Effects of fasting on biperiden pharmacokinetics in the rat. J Pharm Sci 1987;76:10-3.

7. Sanchez SF, Alvarez LI, Lanusse CE. Fasting-induced changes to the pharmacokinetic behaviour of albendazole and its metabolites in calves. J Vet Pharmacol Ther 1997;20:38-47.

8. Affandi MMR, Tripathy M, Majeed ABA. The prospect, promises and hindrances of statin base molecules: look back to look forward. Int J Pharm Pharm Sci 2016;8:22-33.

9. Yamazaki M, Suzuki H, Hanano M, Tokui T, Komai T, Sugiyama Y. $\mathrm{Na}(+)$-independent multispecific anion transporter mediates active transport of pravastatin into rat liver. Am J Physiol 1993;264:G36-44.

10. Tokui T, Nakai D, Nakagomi R, Yawo H, Abe T, Sugiyama Y. Pravastatin, an HMG-CoA reductase inhibitor, is transported by rat organic anion transporting polypeptide, oatp2. Pharm Res 1999;16:904-8.

11. Sanneboina S, Sammeta V, Pingili RB, Kadimpati KK. Influence of lovastatin on pharmacokinetics and pharmacodynamics of glipizide in healthy and streptozotocin-induced diabetic rats: involvement of P-glycoprotein inhibition. Asian J Pharm Clin Res 2016;9:3-8.

12. Yamazaki M, Kobayashi K, Sugiyama Y. Primary active transport of pravastatin across the liver canalicular membrane in normal and mutant Eisai hyperbilirubinemic rats. Biopharm Drug Dispos 1996;17:607-21.

13. Yamazaki M, Akiyama S, Niinuma K. Biliary excretion of pravastatin in rats: contribution of the excretion pathway mediated by canalicular multispecific organic anion transporter. Drug Metab Dispos 1997;25:1123-9.

14. Lagas JS, Sparidans RW, Wagenaar E, Beijnen JH, Schinkel AH. Hepatic clearance of reactive glucuronide metabolites of diclofenac in the mouse is dependent on multiple ATP-binding cassette efflux transporters. Mol Pharmacol 2010;77:687-94.

15. Gupta S, Todd Stravitz R, Pandak WM, Muller M, Reno Vlahcevic Z, Hylemon PB. Regulation of multidrug resistance 2 Pglycoprotein expression by bile salts in rats and in primary cultures of rat hepatocytes. Hepatology 2000;32:341-7.

16. Cheng Q, Aleksunes LM, Manautou JE, Cherrington NJ, Scheffer GL, Yamasaki H. Drug-metabolizing enzyme and transporter expression in a mouse model of diabetes and obesity. Mol Pharm 2008;5:77-91.

17. Yamazaki Y, Hashizume T, Morioka H, Sadamitsu S, Ikari A, Miwa $\mathrm{M}$, et al. Diet-induced lipid accumulation in liver enhances ATP-binding cassette transporter g5/g8 expression in bile canaliculi. Drug Metab Pharmacokinet 2011;26:442-50.

18. Renaud HJ, Cui JY, Lu H, Klaassen CD. Effect of diet on expression of genes involved in lipid metabolism, oxidative stress, and inflammation in mouse liver-insights into mechanisms of hepatic steatosis. PLoS One 2014;9:e88584.

19. Schmitt M, Kubitz R, Wettstein M, vom Dahl S, Haussinger D. Retrieval of the mrp2 gene encoded conjugate export pump from the canalicular membrane contributes to cholestasis induced by tert-butyl hydroperoxide and chlorodinitrobenzene. Biol Chem 2000;381:487-95.

20. Ji B, Ito K, Sekine S, Tajima A, Horie T. Ethacrynic-acid-induced glutathione depletion and oxidative stress in normal and Mrp2deficient rat liver. Free Radical Biol Med 2004;37:1718-29.

21. Sekine S, Ito K, Horie T. Canalicular Mrp2 localization is reversibly regulated by the intracellular redox status. Am J Physiol Gastrointest Liver Physiol 2008;295:G1035-41.

22. Uraki M, Kawase A, Matsushima Y, Iwaki M. Effects of dose, flow rate and bile acid on diclofenac disposition in the perfused rat liver. Eur J Drug Metab Pharmacokinet 2015;41:301-7.

23. Kawase A, Fujii A, Negoro M, Akai R, Ishikubo M, Komura $\mathrm{H}$, et al. Differences in cytochrome P450 and nuclear receptor mRNA levels in liver and small intestine between SD and DA rats. Drug Metab Pharmacokinet 2008;23:196-206.

24. Kawase A, Yamada A, Gamou Y, Tahara C, Takeshita F, Murata K, et al. Increased effects of ginsenosides on the expression of cholesterol 7 alpha-hydroxylase but not the bile salt export pump are involved in cholesterol metabolism. J Nat Med 2013;67:545-53.

25. Baker N, Shipley RA, Clark RE. Incefy GE. C14 studies in carbohydrate metabolism: glucose pool size and rate of turnover in the normal rat. Am J Physiol 1959;196:245-52.

26. Heath DF, Corney PL. The effects of starvation, environmental temperature and injury on the rate of disposal of glucose by the rat. Biochem J 1973;136:519-30.

27. Freminet A, Poyart C, Leclerc L, Gentil M. Effect of fasting on glucose recycling in rats. FEBS Lett 1976;61:294-7.

28. Kikuchi S, Hata M, Fukumoto K, Yamane Y, Matsui T, Tamura A, et al. Radixin deficiency causes conjugated hyperbilirubinemia with loss of Mrp2 from bile canalicular membranes. Nat Genet 2001;31:320-5.

29. Wang W, Soroka CJ, Mennone A, Rahnert C, Harry K, Pypaert M, et al. Radixin is required to maintain apical canalicular membrane structure and function in rat hepatocytes. Gastroenterology 2006;131:878-84.

30. Orr JM, Benet LZ. The effect of fasting on the rate of intestinal drug absorption in rats: preliminary studies. Am J Dig Dis 1975;20:85865.

31. Rothschild MA, Oratz M, Mongelli J, Schreiber SS. Effects of a short-term fast on albumin synthesis studied in vivo, in the perfused liver, and on amino acid incorporation by hepatic microsomes. J Clin Invest 1968;47:2591-9.

32. Yap SH, Hafkenscheid JC. Effect of starvation of the synthesis rate of albumin in vivo and its relation to the concentrations of amino acids in the peripheral blood, the portal circulation and in the liver cytosolic fraction. Ann Nutr Metab 1981;25:158-64.

33. O'Shea D, Davis SN, Kim RB, Wilkinson GR. Effect of fasting and obesity in humans on the 6-hydroxylaton of chlorzoxazone: a putative probe of CYP2E1 activity. Clin Pharmacol Ther 1994;56:359-67.

34. Qu W, Rippe RA, Ma J, Scarborough P, Biagini C, Fiedorek FT, et al. Nutritional status modulates rat liver cytochrome $\mathrm{P} 450$ arachidonic acid metabolism. Mol Pharmacol 1998;54:504-13.

35. Longo V, Ingelman-Sundberg M, Amato G, Salvetti A, Gervasi PG. Effect of starvation and chlormethiazole on cytochrome P450s of rat nasal mucosa. Biochem Pharmacol 2000;59:1425-32.

36. Lammers LA, Achterbergh R, de Vries EM, van Nierop FS, Klumpen HJ, Soeters MR et al. Short-term fasting alters cytochrome P450-mediated drug metabolism in humans. Drug Metab Dispos 2015;43:819-28.

\section{How to cite this article}

- Atsushi Kawase, Ayumi Handa, Masahiro Iwaki. Effects of fastingon pravastatin disposition in perfused rat liver. Int J Pharm Pharm Sci 2016;8(12):130-134. 